\title{
BMJ Open Impact of the COVID-19 pandemic on the utilisation of health services at public hospitals in Yemen: a retrospective comparative study
}

\author{
Mikyias Kotiso, ${ }^{1}$ Naseeb Qirbi, ${ }^{1}$ Kahtan Al-Shabi (D) , ${ }^{2}$ Elena Vuolo, ${ }^{1}$ Ali Al-Waleedi, ${ }^{3}$ \\ Jeremias Naiene, ${ }^{4}$ Mikiko Senga, ${ }^{1}$ Mohammed Khalil, ${ }^{5}$ Huda Basaleem, ${ }^{6}$ \\ Ahmed Alhidary (iD ${ }^{7}$
}

To cite: Kotiso M, Qirbi N, Al-Shabi K, et al. Impact of the COVID-19 pandemic on the utilisation of health services at public hospitals in Yemen: a retrospective comparative study. BMJ Open 2022;12:e047868. doi:10.1136/ bmjopen-2020-047868

- Prepublication history for this paper is available online. To view these files, please visit the journal online (http://dx.doi org/10.1136/bmjopen-2020047868).

Received 18 December 2020 Accepted 15 December 2021

Check for updates

(C) Author(s) (or their employer(s)) 2022. Re-use permitted under CC BY-NC. No commercial re-use. See rights and permissions. Published by BMJ.

${ }^{1}$ WHO, Sana'a, Yemen

${ }^{2}$ WHE, WHO, Sana'a, Yemen

${ }^{3}$ Yemen Ministry of Public Health and Population, Aden, Yemen

${ }^{4}$ WHO, Aden, Yemen

${ }^{5}$ Yemen Ministry of Public Health and Population, Sana'a, Yemen ${ }^{6}$ Department of Community Medicine, University of Aden Faculty of Medicine and Health Science, Aden, Yemen ${ }^{7}$ WHO Yemen, Sana'a, Yemen

Correspondence to

Dr Ahmed Alhidary;

alhidary73@yahoo.com

\section{ABSTRACT}

Background The COVID-19 pandemic has led to a global crisis, creating an unprecedented situation, which has taken the world by storm, overshadowing on all life' aspects and having a significant impact on the health systems of most countries. In this study, the delivery of health services is investigated both before and during the outbreak of the COVID-19 pandemic at public hospitals in Yemen to assess the impact of COVID-19 on the utilisation of health services.

Method Data collected from 127 hospitals in Yemen were reviewed using the DHIS2 system. The data represented 3 months before the outbreak of COVID-19 between January and March 2020 and during the outbreak of COVID-19 outbreak between April and June 2020. The results were then compared with the same period in 2019. The utilisation pattern of healthcare services during the period of investigation was compiled and analysed by applying a generalised estimating equation (GEE) to examine the effects of the COVID-19 outbreak in Yemen. The data collected from the targeted hospitals included information related to consultations, surgeries, deliveries, C-sections and penta-3rd dose immunisation.

Results The trendline of health services used during the pandemic showed a gradual decline beginning from April 2020 for consultations, surgeries and penta-3rd dose utilisation. The GEE model revealed a significant effect $(p<0.05)$ during the outbreak compared with preoutbreak in the consultation services $(B=-1,343.9 ; 95 \% \mathrm{Cl}$ $-1,767.2$ to $-920.6 ; \chi^{2}=38.718$ ), surgeries $(B=-54.98$; $95 \% \mathrm{Cl}-79.13$ to $\left.-30.83, \chi^{2}=19.911\right)$ and penta-3rd dose $\left(\mathrm{B}=-24.47 ; 95 \% \mathrm{Cl}-30.56\right.$ to -18.38 and $\left.\chi^{2}=62.010\right)$. As for deliveries and C-sections, the results were shown to be statistically non-significant.

Conclusion The impact of COVID-19 on continuity of health services delivery in Yemen has been distinct and profound, where the study revealed that the number of the consultations, surgeries and number of vaccinated children have been declined during the COVID-19 pandemic, likely due to the partially lockdown measures taken and fear of being infected. However, the deliveries and C-section services remained nearly in the same level and did not affect by the COVID-19 pandemic.

\section{Strengths and limitations of this study}

- The raw data have been manually gathered through three sources to enhance the data quality.

- The data were collected from the largest hospitals in Yemen that served the $46 \%$ of the population to enhance the external validity.

- A comparison was made between the same hospitals' pre-COVID-19 and during COVID-19 outbreak periods that minimise selection bias and enhance the internal validity.

- The study is a unique study because it has been carried out in a country that has turned by domestic armed conflicts.

- The study will contribute to provide a better understanding of the services more affected due to the pandemic.

\section{BACKGROUND}

The Ministry of Health (MoH) and other stakeholders in Yemen have sought to achieve the stability of health services in the country, despite the country's ongoing armed conflict, huge displacement and the fragile and exhausted health system in the country. The $\mathrm{MoH}$ and stakeholders are concerned about providing trauma care and improving access to basic healthcare services and provision of essential and life saving health services for Yemeni population in needs. ${ }^{1}$

The COVID-19 pandemic has rapidly spread to all countries leading to a global crisis that caught many countries off-guard in preparing for such a crisis and impacting the lives of everyone, ${ }^{1}$ where the most countries have economically impacted and desperately exhausted. ${ }^{23}$ Since the outbreak in late 2019 to early 2020, within a very short period of a few months, more than one-third of the world's population has been under lockdown and movement restrictions. ${ }^{4}$ Globally, as of 
the 5 October 2020, there have been around 35027546 confirmed cases of COVID-19, including 1034837 deaths. $^{5}$

In Yemen, the first reported case of COVID-19 was on the 10 April 2020. ${ }^{1}$ Since then, as at 5 October 2020, there have been 2045 confirmed cases of COVID-19, including 592 deaths. ${ }^{56}$ The rapid spread of COVID-19 confirmed cases in Yemen has subsequently led to an extraordinary situation, shifting the attention and efforts towards a united response to COVID-19 pandemic. ${ }^{17}$ The United Nations (UN) agencies in Yemen have also expressed concern about the potential decline of donor support, which may lead to a decline or disrupt the support of basic health programmes in the country. ${ }^{78}$ However, the majority of staff involved in the management of COVID-19 isolation centres who are healthcare and medical staff in hospitals are already suffering from the imbalance of low skilled health professionals and skills mix. ${ }^{9}$ Some people's perceptions of the hospitals have changed from places of safety to one of dangerous locations. So, they are avoiding visiting hospitals due to COVID-19 fears. ${ }^{10}$

Pandemic diseases nowadays pose a significant threat and challenge to health systems, ${ }^{11}$ particularly in war-torn countries like Yemen, having a poor healthcare system, ${ }^{12}$ where the WHO described the outbreak of COVID-19 in Yemen as 'highly catastrophic' in a country that is already highly fragile after more than 5 years of civil conflict. ${ }^{13}$ To the best of our knowledge, this is the first study to assess the impact of the COVID-19 pandemic on continuity of health services delivery in Yemen or other surrounding countries. This has motivated the need for this study to be undertaken, specifically to assess the trends concerning the utilisation of health services before and during the outbreak of COVID-19 and to ascertain whether the data pattern observed during the pandemic is different to that observed before the outbreak. This will also satisfy the aim of this study to evaluate the impact of COVID-19 on the continuity of the health services provision at public hospitals in Yemen. Accordingly, this study will contribute to provide a better understanding of the effect of COVID-19 on the utilisation of health services and which services have been more affected, resulting from the pandemic.

\section{Setting}

Yemen has 22 governorates that are divided into 333 districts. The health services in Yemen are provided via a variety of healthcare facilities, classified across three levels of health services, namely: (1) first level: includes 3573 health units and 1164 health centres; (2) second level: includes 228 district and interdistrict hospitals; and (3) tertiary level: includes 36 general and referral hospitals, 10 maternal hospitals and 4 psychiatric hospitals. ${ }^{14}$ In the current study, the data of the second and third levels of health facilities were reviewed.

\section{Study design, population and period}

A retrospective comparative study using routinely hospital services data, from January to June during the years 2019 and 2020. The data have been reviewed from 127 hospitals. There were 127 eligible hospitals included in this study, which included hospitals that were fully functional, had access to the District Health Information Software (DHIS2) system, adhered to send the data and had health facilities in second and tertiary levels. Therefore, the data collected from 127 hospitals in Yemen were collected from the medical records by using the DHIS2 system and by phone to verify if there were differences between the two sources. The data represented 3 months before the outbreak of COVID-19 between January and March 2020 and during the outbreak of COVID-19 outbreak between April and June 2020, as reflected in figure 1. The period chosen for the review was premised on the COVID-19 outbreak and the first case reported by the $\mathrm{MoH}$ in Yemen on 10 April 2020.

\section{Sample size and sampling technique}

The data have been collected from the 127 eligible hospitals, as mentioned earlier (representing 46\%), were compiled and used in this study. The hospitals had been sending data to the WHO office during 2019 and 2020 on the status of COVID-19 reported cases. The hospitals included 31 (86\%) general hospitals (GHs), 2 (20\%) maternal and children hospitals (MCHs) and $3(75 \%)$ psychiatric hospitals (Psych H) and included 91 (40\%) district hospitals (DHs). The bed capacity of the selected hospitals included 2465 beds, receiving around 534132 patients each month.

\begin{tabular}{|c|c|c|c|c|c|c|}
\hline Jan-20 & Feb-20 & March-20 & Apr-20 & May-20 & Jun-20 & \multirow[t]{2}{*}{ Year 2020} \\
\hline \multicolumn{3}{|c|}{ Quarter 1, Pre pandemic } & \multicolumn{3}{|c|}{ Quarter 2, during the pandemic } & \\
\hline Jan-19 & Feb-19 & March-19 & Apr-19 & May-19 & Jun-19 & Year 2019 \\
\hline
\end{tabular}

Quarter land 2, comparison period 2019

Figure 1 Data collection timeframe from the targeted hospitals. The used data represent the 3 months before the outbreak of COVID-19 in Yemen, January-March 2020, and the 3months during the COVID-19 outbreak, April and June 2020. The results were then compared with the same period of the year 2019, January-June. 


\section{Data collection}

The data were collected manually from the targeted hospitals and extracted from the DHIS2 android application that follow the WHO office and $\mathrm{MoH}$ in Yemen and by phone to verify if there were differences abetween the two sources. Regarding missing data, the monitoring and evaluation officers at WHO communicated with the hospital statisticians by phone in order to follow-up on the missing data. The missing data retrieved from the statistical department of each hospital were then cleaned, screened and reviewed. The output retrieved from the targeted hospitals included consultations, surgeries, deliveries, C-sections and penta-3rd dose immunisation.

\section{Patient and public involvement}

To identify priority and gap in the Yemeni health system during the COVID-19 outbreak, we worked with stakeholders of health services provision. $\mathrm{MoH}$ and WHO staff participated in research methodology and provide us with the required data. They also participated in analysis of the secondary data. The results provided an overview about the situation in Yemen during the pandemic and the humanitarian crisis in the country. The participants transformed the study findings to recommendations will be taken in consideration in the second wave of the pandemic. The patients were not involved in the study, because we used secondary data for the analysis.

\section{Statistical analysis}

The data were presented in trendlines using Microsoft Excel (2016) from the data series to display the data graphically. The trendlines showed a visual representation of trends associated with the utilisation of services for the period between January and June in 2019 compared with the same 6-month period in 2020. The study variables were summarised as the mean and SD for the utilisation of the services by each governorate. The generalised estimating equation (GEE) was used to gauge the effects and whether the COVID-19 outbreak had any impact on the changes in the utilisation of services for the years compared. The exchangeable correlation matrix was used, and the Wald test $\left(\chi^{2}\right)$ determined the level of significance at 0.05 .

\section{RESULTS}

General description

The data have been reviewed from 134 hospitals; seven hospitals were excluded due to large amounts of missing data. The eligible hospitals were 127 hospitals that included $31 \mathrm{GHs}, 2 \mathrm{MCHs}, 3$ Psych Hs and $91 \mathrm{DHs}$. The hospitals provided data reporting on the number of consultations, 110 reporting surgeries, 112 reporting delivery cases and 64 hospitals reporting on C-sections surgeries and 107 reporting on penta-3rd dosages. The analysis covered 21 governorates from 22 governorates across Yemen. As can be seen in table 1, the cumulative sum of consultations was 6409583 between January and June 2019 and for the same period in 2020. Of these, there were 255494 surgeries, 144432 deliveries, 422050 C-sections and 66969 children who had received an immunisation (third dose of pentavalent vaccine).

\section{Effects of COVID-19 on the utilisation of services}

Figure 2 consists of five graphs showing the trendlines for the utilisation of health services in the selected hospitals for the periods under investigation. The trendlines for consultations, surgeries and vaccinations in the prepandemic period of 2020 gradually decreased but remained higher compared with the same period in 2019. For the 'during' pandemic period of 2020, the trendlines dropped sharply to be less than that for the same period in 2019, where it recorded the lowest value in May, after that the trend started to increase in June gradually. The trendline for deliveries and C-section services in 2020 was

Table 1 Overview of number of health services delivered, January-June, 2019 and 2020

\begin{tabular}{|c|c|c|c|c|c|c|c|c|c|c|}
\hline \multirow[b]{2}{*}{ Statement } & \multicolumn{2}{|c|}{$\begin{array}{l}\text { Consultations* } \\
127 \text { Hospitals }\end{array}$} & \multicolumn{2}{|c|}{$\begin{array}{l}\text { Surgeryt } \\
110 \text { Hospitals }\end{array}$} & \multicolumn{2}{|c|}{$\begin{array}{l}\text { Deliveries } ¥ \\
112 \text { Hospitals }\end{array}$} & \multicolumn{2}{|c|}{$\begin{array}{l}\text { C-sections } \\
64 \text { Hospitals }\end{array}$} & \multicolumn{2}{|c|}{$\begin{array}{l}\text { Penta-3rd dose } \\
107 \text { Hospitals }\end{array}$} \\
\hline & $2019 \S$ & $2020^{5}$ & 2019* & $2020 t$ & 2019* & $2020 t$ & 2019* & $2020 t$ & $2019^{*}$ & $2020 t$ \\
\hline February & 553410 & 635718 & 22642 & 24427 & 10785 & 13100 & 3005 & 4095 & 5854 & 6326 \\
\hline March & 587732 & 597296 & 24724 & 22480 & 11296 & 12609 & 3206 & 3865 & 6373 & 6552 \\
\hline June & 551365 & 384418 & 20501 & 15131 & 13216 & 11038 & 3386 & 3397 & 5146 & 4497 \\
\hline Total & 3271878 & 3137705 & 134525 & 120969 & 70832 & 73600 & 19356 & 22694 & 34642 & 32327 \\
\hline
\end{tabular}

${ }^{*}$ All beneficiaries who visited the clinic or emergency room in a health facility in specific period to meet a health professional practitioner during the working hours for diagnosis, treatment, general check-up or advice.

†Surgeries include major and minor surgeries.

\#Year of 2019 is the comparison period and included the months from January to Jan.

§Year of 2020 is the study year and included prepandemic period that included months from January to March and during pandemic which included the months from April to June. 

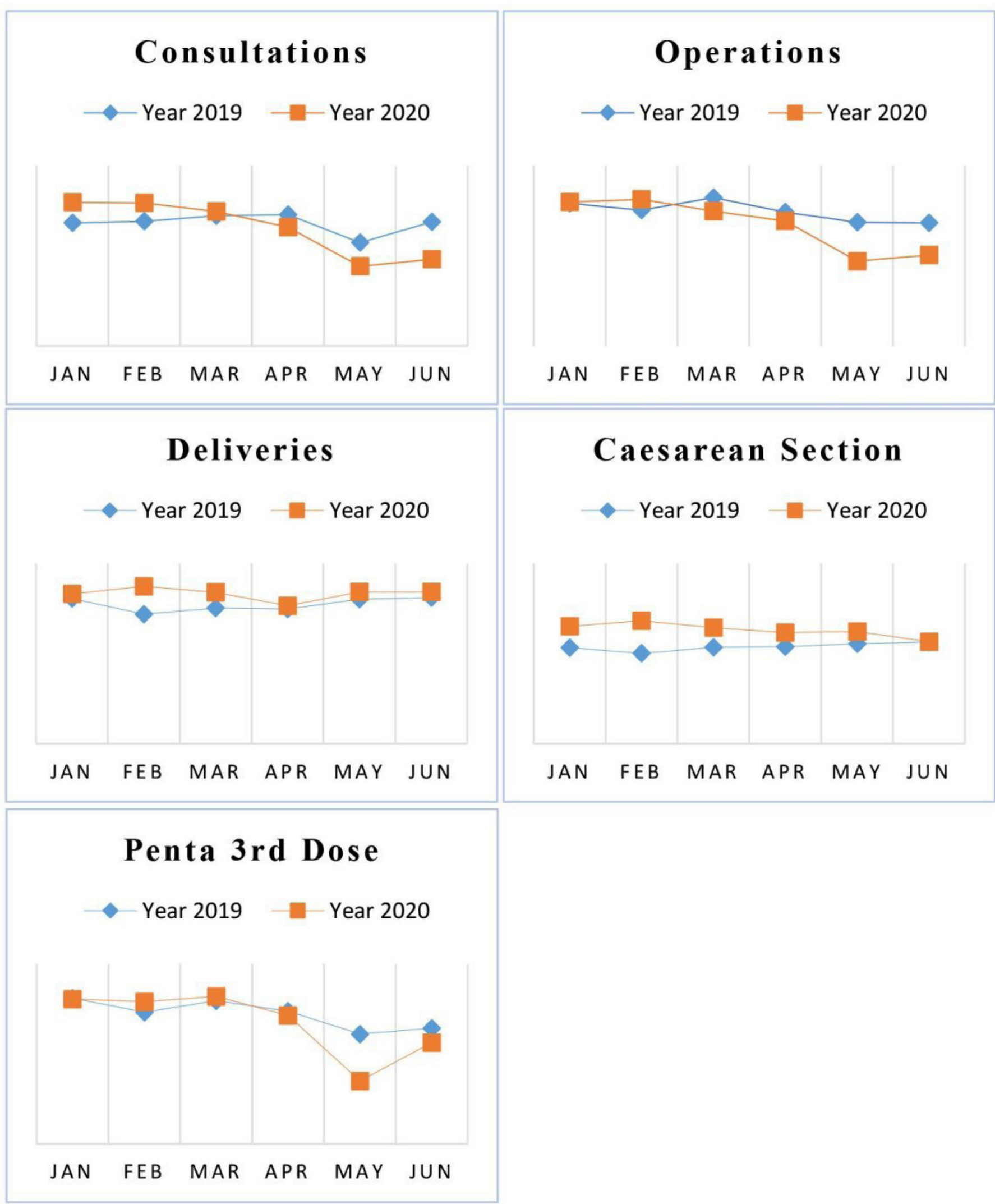

Figure 2 The trends of the five health services in pre-COVID-19 and during the COVID-19 outbreak compared with the same period of the year 2019. Note that the results showed that the consultations, surgeries and vaccinated children number have been declined during the COVID-19 pandemic. In regards to the C-section, services remained nearly in the same level, and did not affect by the COVID-19 pandemic. 
marginally higher than for 2019, where the trendlines for the periods in 2019 and 2020 were in parallel (deliveries $\mathrm{r}=0.97$ and $\mathrm{C}$-sections $\mathrm{r}=0.91$ ).

The GEE linear analysis used to test the effect of time in the total sample revealed that the difference between the twoyears (2019 and 2020) was statistically non-significant $(p>0.05)$ in the pre-COVID 19 outbreak period and slightly effect in March for the surgery utilisation $\left(B=-32.28 ; 95 \% \mathrm{CI}-60.73\right.$ to $\left.-3.84 ; \chi^{2}(1)=4.949\right)$ and the penta-3rd provided in February $(\mathrm{B}=-3.46 ; 95 \%$ CI -6.63 to $\left.-0.29 ; \chi^{2}(1)=4.567\right)$. During the COVID-19 outbreak, the results appeared to show that the effect was statistically significant with a higher effect in May, where the results revealed that the utilisation of consultation services was $(\mathrm{B}=-1343.9 ; 95 \% \mathrm{CI}-1767.2$ to -920.6 ; $\left.\chi^{2} \quad(1)=38.718\right)$, surgeries $(B=-54.98 ; 95 \% \mathrm{CI}-79.13$ to $\left.-30.83, \chi^{2}(1)=19.911\right)$ and $(B=-24.47 ; 95 \%$ CI -30.56 to $\left.-18.38, \chi^{2}(1)=62.010\right)$. The deliveries and C-section results statistically were non-significant in the prepandemic and during the pandemic $p>0.05$. Refer to table 2 for further details.

\section{DISCUSSION}

The WHO and other health stakeholders have been collaborating and working closely with the $\mathrm{MoH}$ in Yemen to achieve stability in the provision of basic health services. ${ }^{1516}$ However, unfortunately, the emergence of COVID-19 has caused a situation of great significance to occur, impacting the health and well-being of the country. ${ }^{17}$ However, the fast transmission of COVID-19 and spread rumours have made people reluctant of visiting hospitals due to fear of getting contagion and transmission of the virus. ${ }^{17}$ As COVID-19 outbreack started, many countries around the world applied lockdown and social restriction policies in order to contain spread of the infection, which had negatively impacted on health services utilisation. ${ }^{18-21}$ However, in Yemen, the country did not enforce the lockdown policies and did not restrict people's movements due to the lack of coordination between the government administrations and daily working nature of people. ${ }^{22}$ Moreover, the authorities in the north part of Yemen have been refused to admit the full scale of the COVID-19 outbreak. ${ }^{13}$ In this study, we endeavoured to assess the effect of the COVID-19 outbreak on the utilisation of health services before and during the COVID-19 outbreak in Yemen in comparison with the same period in 2019.

The data collected from hospitals and analysed indicated that there was an increase in the number of consultations by $134173(4 \%)$ in 2020 compared with the same period in 2019. Similarly, 110 and 107 of those hospitals reported an increase in conducted surgeries by 13556 (10\%) and penta-3rd vaccinations provided by $2315(7 \%)$, respectively, in 2019 compared with the prepandemic and during the pandemic period for 2020. In contrast, the hospitals reported an increase in deliveries and C-sections by $5350(7 \%)$ for deliveries and $3338(15 \%)$ for C-sections in 2020 compared with 2019.

By observing the trendline in figure 2, in the prepandemic, it appeared that the utilisation of consultations, surgeries and penta-vaccination services for the period examined in 2020 were higher than for the same period in 2019. During the pandemic in 2020, the utilisation of services gradually declined to be the lowest in May 2020 compared with the other months in that period under examination and less than for the same period in 2019. The GEE regression model also had revealed a significant effect during the pandemic (2020) compared with the prepandemic period under examination, where the value of the $\chi^{2}$ was higher than that of the prepandemic period. Accordingly, the results indicated that consultations, surgeries and penta-vaccination services had declined in the 'during' pandemic period in Yemen.

These findings are consistent with several other studies that have been undertaken to evaluate the impact of COVID-19 on health services. In a study conducted in Yemen, the study indicated that there are some precaution procedures that have been taken, such as education activites have been suspended, the universities and schools have been closed and the movement among cities have been restricted. ${ }^{23}{ }^{24}$ Abdela et al and Nair et al found that there is a significant effect on the admission of in-patients to outpatient departments, dental services, surgical care and ophthalmic care. ${ }^{25-27}$ In another study, Al-Jabir $e t a l^{28}$ evaluated the impact of COVID-19 on surgeries finding that there was a profound impact brought about by COVID-19 on surgical practices and the education of surgeons. In an article published by Long and Corsar, they presented an interpretation of the reasons for the low attendance of patients in hospitals during the COVID-19 outbreak. Here, they reported that the reasons for low attendance during the outbreak of COVID-19 were attributed to the patient's desire to avoid hospitals because of fear of infection. ${ }^{29}$ In another study by Chou et al, they assessed the impact of COVID-19 on hospital admissions, discovering that patient admissions during COVID-19 decreased..$^{30}$

In contrast, in the current study, the number of deliveries and C-sections in prepandemic and during the pandemic period in 2020 were slightly higher compared with the same period in 2019. Thus, the effect was statistically non-significant both prepandemic and during the pandemic. Therefore, it can be concluded that the results indicate that both deliveries and C-section services have not changed significantly during the pandemic, meaning that these services have not been affected by the COVID-19 outbreak.

These findings are supported by a study conducted in Ethiopia, where the authors found that the delivery service was relatively stable during the COVID-19 outbreak compared with other services. ${ }^{27}$ In a similar study that investigated the impact of the outbreak of Ebola on maternal health services, the authors highlighted that there was a relatively stable number of patients attending 
Table 2 Results of the liner GEE model, the effect of COVID-19 outbreak on the services utilisation*, df $\dagger=1$

\begin{tabular}{|c|c|c|c|c|c|c|}
\hline Dependent variables & Parameters & B & SE & 95\% Cl¥ & $\chi^{2}$ & Sig \\
\hline \multirow[t]{5}{*}{ Consultations } & Intercept & 4573.81 & 552.06 & 3491.8 to 5655.8 & 68.642 & $<0.001$ \\
\hline & Condition§ & $1,76.69$ & 140.84 & -99.4 to 452.7 & 1.574 & 0.21 \\
\hline & March & 38.84 & 117.35 & 191.2 to 268.8 & 0.110 & 0.74 \\
\hline & April & -284.54 & 126.30 & -532.1 to -36.9 & 5.075 & 0.02 \\
\hline & Jun & -977.9 & 188.44 & -1347.3 to -608.6 & 26.934 & $<0.001$ \\
\hline \multirow[t]{5}{*}{ Surgeries } & Intercept & 215.99 & 38.72 & 140.10 to 291.88 & 31.114 & $<0.001$ \\
\hline & Condition§ & 30.25 & 14.92 & 1.01 to 59.49 & 4.111 & 0.043 \\
\hline & February & -27.50 & 14.81 & -56.54 to 1.53 & 3.448 & 0.063 \\
\hline & March & -32.28 & 14.51 & -60.73 to -3.84 & 4.949 & 0.026 \\
\hline & Jun & -85.03 & 26.03 & -136.05 to -34.02 & 10.673 & 0.001 \\
\hline \multirow[t]{7}{*}{ Penta-3rd dose } & Intercept & 58.57 & 6.30 & 46.21 to 70.93 & 86.309 & 0.000 \\
\hline & Condition§ & 3.61 & 1.75 & 0.18 to 7.03 & 4.263 & 0.039 \\
\hline & February & -3.46 & 1.62 & -6.63 to -0.29 & 4.567 & 0.033 \\
\hline & March & 0.02 & 2.22 & -4.32 to 4.37 & 0.000 & 0.992 \\
\hline & April & -6.09 & 2.18 & -10.36 to -1.82 & 7.799 & 0.005 \\
\hline & May & -24.47 & 3.11 & -30.56 to -18.38 & 62.010 & 0.000 \\
\hline & Jun & -15.31 & 2.48 & -20.18 to -10.45 & 38.075 & 0.000 \\
\hline Deliveries & Intercept & 112.71 & 12.45 & 88.32 to 137.11 & 81.985 & 0.000 \\
\hline \multirow[t]{7}{*}{ C-sections } & Intercept & 60.78 & 8.24 & 44.62 to 76.94 & 54.344 & 0.000 \\
\hline & Condition§ & -8.83 & 3.43 & -15.56 to -2.11 & 6.624 & 0.010 \\
\hline & February & -0.02 & 1.83 & -3.60 to 3.57 & 0.000 & 0.993 \\
\hline & March & -0.25 & 2.41 & -4.96 to 4.47 & 0.010 & 0.919 \\
\hline & April & -1.37 & 2.63 & -6.51 to 3.78 & 0.270 & 0.603 \\
\hline & May & -0.30 & 2.25 & -4.70 to 4.10 & 0.018 & 0.893 \\
\hline & Jun & -2.53 & 2.57 & -7.58 to 2.51 & 0.968 & 0.325 \\
\hline
\end{tabular}

January was used as reference.

*Dependent variable: surgeries, probability distribution: normal, number of hospitals: model: (Intercept), condition, months, working correlation matrix structure: exchangeable.

tdf is degree of freedom.

$\$ 95 \% \mathrm{Cl}$ : if the $95 \% \mathrm{Cl}$, contains zero (null value), then there are no statistical significant differences.

$\S$ Condition is the COVID-19 period (2020) and comparison period (2019).

hospitals during the pandemic. The volume of deliveries and C-sections in Yemen were similar to the numbers recorded for the pre-Ebola period. ${ }^{31}$ However, a study conducted in Nepal reported a decline in the number of maternal health services during the COVID-19 outbreak due to enforced lockdowns, restrictions on transport, closure of outpatient services, movement restrictions placed on relatives accompanying pregnant women admitted to hospital for admission or other medical treatment. ${ }^{32}$

There were several limitations inherent in this study. One limitation concerns the study sample as it did not 
include all hospitals in Yemen since only $52 \%$ of health facilities in Yemen have been fully functioning at the time of this study. ${ }^{14}$ A second limitation is that the targeted hospitals were selected employing a non-randomised sampling method, which may affect the external and internal validity. However, these hospitals represented $46 \%$ of health facilities at the second and third levels of health services, covering 21 of the 22 Yemeni governorates, thereby minimising threats to external validity. Moreover, rigorous procedures were followed by collecting information via the hospitals' statisticians, who confirmed the information from various sources, which also included reviewing and cleaning the data by active monitoring and evaluation. Also, a comparison was made between the same hospital's prepandemic and during COVID-19 outbreak periods, which minimised selection bias and minimised the threat to the internal validity of the data. Third, the data of COVID-19 were not taken as a control to minimise the confounding variables, because the hospitals in the north part of country refused to share us the data COVID-19.

\section{Conclusion}

The impact of COVID-19 on continuity of health services delivery in Yemen has been distinct and profound, where the study revealed that the number of the consultations, surgeries and number of vaccinated children have been declined during the COVID-19 pandemic, likely due to the partially lockdown measures taken and fear of being infected. However, the deliveries and C-section services remained nearly in the same level and were affected by the COVID-19 pandemic. This means that some services remain obligatory and necessary, and clients cannot postpone them, so it is obligatory for the health decision makers to take in consideration keeping those services continuity access during outbreaks or emergency situations.

Acknowledgements We would to thank the M\&E officers in the WHO and statisticians in the Ministry of Health ( $\mathrm{MOH})$ who spent their valuable time in verification of the monthly data of the targeted health facilities. We would like to thank Yemen MOH and WHO Yemen office for their valauble support and help us to access the data after revision and verification to ensure the quality of the data. We would also like to acknowledge Dr Nuha Mahmoud, manager of WHO Aden office, for her support and help. Lastly, we would like to thank Mr Paul Bahnisch for his assistance to proofread and edit the English version of this paper.

Contributors AAh, MK and HB designed the study. NQ, EV and MS reviewed the methodology. MK, JN, AALW and KA organised the data. AAh, MK and MS carried out the analysis. All authors contributed to manuscript writing and reviewing.

Funding The authors have not declared a specific grant for this research from any funding agency in the public, commercial or not-for-profit sectors.

Competing interests None declared.

Patient and public involvement Patients and/or the public were not involved in the design, or conduct, or reporting, or dissemination plans of this research.

Patient consent for publication Not applicable.

Ethics approval Ethical approval was sought from the MoH before initiating the study.

Provenance and peer review Not commissioned; externally peer reviewed.
Data availability statement All data relevant to the study are included in the article or uploaded as supplementary information.

Open access This is an open access article distributed in accordance with the Creative Commons Attribution Non Commercial (CC BY-NC 4.0) license, which permits others to distribute, remix, adapt, build upon this work non-commercially, and license their derivative works on different terms, provided the original work is properly cited, appropriate credit is given, any changes made indicated, and the use is non-commercial. See: http://creativecommons.org/licenses/by-nc/4.0/.

ORCID iDs

Kahtan Al-Shabi http://orcid.org/0000-0001-5139-9857

Ahmed Alhidary http://orcid.org/0000-0001-9300-3259

\section{REFERENCES}

1 Al-Awlaqi S, Dureab F, Annuzaili D, et al. COVID-19 in conflict: the devastating impact of withdrawing humanitarian support on universal health coverage in Yemen. Public Health Pract 2020;1:100015.

2 Liu N, Zhang F, Wei C, et al. Prevalence and predictors of PTSS during COVID-19 outbreak in China hardest-hit areas: gender differences matter. Psychiatry Res 2020;287:112921.

3 Thapa SB, Mainali A, Schwank SE, et al. Maternal mental health in the time of the COVID-19 pandemic. Acta Obstet Gynecol Scand 2020;99:817-8

4 Kang L, Li Y, Hu S, et al. The mental health of medical workers in Wuhan, China dealing with the 2019 novel coronavirus. Lancet Psychiatry 2020;7:e14.

5 WHO. WHO health emergency, coronavirus disease (COVID-19) dashboard [online], 2020. Available: https://covid19.who.int/?gclid= CjwKCAjwsO_4BRBBEiwAyagRTYnK6ugKU4m2hWG8vQIUUEE6sKI oyKZRqmYWX'0EvVuT6-Psukup-6xoCJ60QAvD_BwE [Accessed 22 Jul 2020].

6 Dong E, Du H, Gardner L. An interactive web-based dashboard to track COVID-19 in real time. Lancet Infect Dis 2020;20:533-4.

7 Bennett C. United nations office for the coordination of humanitarian Affairs (UNOCHA) orientation handbook. United Nations Office for the Coordination of Humanitarian Affairs (UNOCHA), 2002.

8 Amid funding shortfall, life-saving aid operations for 24 million people in Yemen. United nations office for the coordination of humanitarian Affairs (OCHA) 2020.

9 MoPHP. The national health human resource strategy 2014 - 2020. In: Department HR, editor. Sana'a: MoPHP, 2014.

10 WongLaura E, HawkinsJessica E, MurrellKaren L. Where are all the patients? Addressing Covid-19 fear to encourage sick patients to seek emergency care. NEJM Catalyst Innovations Care Delivery 2020.

11 Zhang Y-F, Qiu Y, He J-S. Impact of COVID-19 outbreak on the care of patients with inflammatory bowel disease: a comparison before and after the outbreak in South China 2020.

12 Qirbi N, Ismail SA. Health system functionality in a low-income country in the midst of conflict: the case of Yemen. Health Policy Plan 2017;32:911-22.

13 Devi S. Fears of "highly catastrophic" COVID-19 spread in Yemen. Lancet 2020;395:1683.

14 WHO. Health resources and services availability mapping system 2018 (HeRAMS). Sana'a: WHO and MOH, System IM, 2018.

15 WHO Yemen. WHO annual report 2017 Yemen [online], 2017. Available: https://www.who.int/emergencies/crises/yem/yemenannual-report-2017.pdf?ua=1 [Accessed 19 Sep 2020].

16 McMaster D, Bamashmus MA. Ophthalmic services during ongoing conflict: the eye health system in Yemen. BMJ Glob Health 2019;4:e001743.

17 Singh DR, Sunuwar DR, Shah SK, et al. Impact of COVID-19 on health services utilization in Province-2 of Nepal: a qualitative study among community members and stakeholders. BMC Health Serv Res 2021;21:174.

18 Raman R, Rajalakshmi R, Surya J, et al. Impact on health and provision of healthcare services during the COVID-19 lockdown in India: a multicentre cross-sectional study. BMJ Open 2021;11:e043590.

19 Conlon C, McDonnell T, Barrett M, et al. The impact of the COVID-19 pandemic on child health and the provision of care in paediatric emergency departments: a qualitative study of frontline emergency care staff. BMC Health Serv Res 2021;21:279.

20 Simon J, Helter TM, White RG, et al. Impacts of the Covid-19 lockdown and relevant vulnerabilities on capability well-being, mental health and social support: an Austrian survey study. BMC Public Health 2021;21:314. 
21 Brown A, Flint SW, Kalea AZ, et al. Negative impact of the first COVID-19 lockdown upon health-related behaviours and psychological wellbeing in people living with severe and complex obesity in the UK. EClinicalMedicine 2021;34:100796.

22 Noushad M, Al-Saqqaf IS. COVID-19: is herd immunity the only option for fragile Yemen? Int J Infect Dis 2021;106:79-82.

23 Al-Baadani AA, Abbas M. The impact of coronavirus (Covid19) pandemic on higher education institutions (HEls) in Yemen: challenges and recommendations for the future. Eur J Educ Stud $2020 ; 7$.

24 COVID-19 movement restrictions: Yemen mobility restriction dashboard \#29 [online]. OCHA, ReliefWeb, 2021. Available: https:// reliefweb.int/report/yemen/covid-19-movement-restrictions-yemenmobility-restriction-dashboard-29-30-september [Accessed 30 Sep 2021].

25 Nair A, Gandhi R, Natarajan S. Effect of COVID-19 related lockdown on ophthalmic practice and patient care in India: results of a survey. Indian J Ophthalmol 2020;68:725-30.

26 Sanjay S, Garg A, Shetty R, et al. Impact of COVID-19 on a tertiary eye hospital. Indian J Ophthalmol 2020;68:1485-6.
27 Abdela SG, Berhanu AB, Ferede LM, et al. Essential healthcare services in the face of COVID-19 prevention: experiences from a referral hospital in Ethiopia. Am J Trop Med Hyg 2020;103:1198-200.

28 Al-Jabir A, Kerwan A, Nicola M, et al. Impact of the Coronavirus (COVID-19) pandemic on surgical practice - Part 1. Int J Surg 2020;79:168-79.

29 Long L, Corsar K. The COVID-19 effect: number of patients presenting to the mid Yorkshire hospitals OMFS team with dental infections before and during the COVID-19 outbreak. $\mathrm{Br} J$ Oral Maxillofac Surg 2020;58:713-4.

30 Chou Y-C, Yen Y-F, Feng R-C, et al. Impact of the COVID-19 pandemic on the utilization of hospice care services: a cohort study in Taiwan. J Pain Symptom Manage 2020;60:e1-6.

31 Quaglio G, Tognon F, Finos L, et al. Impact of Ebola outbreak on reproductive health services in a rural district of Sierra Leone: a prospective observational study. BMJ Open 2019;9:e029093.

32 Kc A, Gurung R, Kinney MV, et al. Effect of the COVID-19 pandemic response on intrapartum care, stillbirth, and neonatal mortality outcomes in Nepal: a prospective observational study. Lancet Glob Health 2020;8:e1273-81. 